DOI: http://dx.doi.org/10.18764/2358-4319.v13n2p116-132

\title{
A motivação como fator essencial na aprendizagem da Língua Inglesa
}

\author{
Elvira Livonete Costa ${ }^{1}$
}

José Elias Pinheiro Neto²

\section{RESUMO}

Este trabalho é resultado de uma pesquisa exploratória acerca dos fatores que influenciam na aprendizagem da Língua Inglesa, para tanto, investiga o processo que promove o interesse dos alunos em relação às aulas de inglês. $\mathrm{O}$ objetivo deste trabalho é apresentar um panorama do complexo universo dos estímulos motivacionais que norteiam o comportamento humano. Fundamentados pelos estudos de Lambert e Gardner, buscamos pensar nos caminhos que possibilitam o sucesso dos alunos na aprendizagem de uma língua estrangeira e, por conseguinte, viabilizam meios de aprimorar as técnicas docentes em sala de aula com o intuito de atingir o interesse dos alunos. Ademais, empreendemos uma reflexão acerca dos aspectos geracionais que fomentam o êxito no ensino da língua inglesa. A metodologia utilizada é a de uma revisão bibliográfica que dentre os principais autores podemos destacar: Veiga (2007), Almeida Filho (2005), Rosa (2007) e Witter (2004) e Gardner (2001).

Palavras-chave: Aprendizagem. Língua Inglesa. Motivação.

\section{Motivation as an Essential Factor in Learning the English Language}

\section{ABSTRACT}

This paper is an exploratory research about the factors that influence the learning of the English Language, in order to investigate the process that

1 Mestra em Letras - Literatura e Crítica Literária pela Pontifícia Universidade Católica - PUC GO. Professora no Curso de Pedagogia na Faculdade Itapuranga - FAI Professora de Língua Inglesa da Rede Estadual de Educação de Goiás. E-mail: elvira-livonete@hotmail.com

2 Doutor em Ciências Humanas pela Universidade de São Paulo - (FFLCH/USP). Estágio Pósdoutoral em andamento em Humanidades e Ciências Sociais Aplicadas do Programa de Pós-Graduação Integração da América Latina da Universidade de São Paulo (PROLAM/USP). Professor na Universidade Estadual de Goiás, Programa de Pós-graduação Stricto Sensu em Língua, Literatura e Interculturalidade (POSLLI).E-mail: Email: joseeliaspinheiro@gmail.com 
promotes students' interest in English classes. The objective is to present an overview of the complex universe of motivational stimuli that guide human behavior, based on the studies of Lambert and Gardner, we seek to think of the ways that students can succeed in learning a foreign language and, therefore, teaching techniques in the classroom in order to reach the students' interest. In addition, we undertake a reflection about the generational aspects that promote the success in the teaching of the English language. The methodology used is a bibliographical review that among the main authors we can highlight: Veiga (2007), Almeida Filho (2005), Rosa (2007) e Witter (2004) and Gardner (2001).

Keywords: Learning. English Language. Motivation.

\section{La Motivación como Factor Esencial en el Aprendizaje del Lengua Inglesa}

\section{RESUMEN}

Este trabajo es resultado de una investigación exploratoria acerca de los factores que influyen en el aprendizaje de la lengua inglesa, por lo tanto, investiga el proceso que promueve el interés de los alumnos con respecto a las clases de inglés. El objetivo de este trabajo es presentar un panorama del complejo universo de los estímulos motivacionales que orientan el comportamiento humano. Basado en los estudios de Lambert y Gardner, buscamos pensar en los caminos que posibilitan el éxito de los alumnos en el aprendizaje de una lengua extranjera y, por consiguiente, se hacen viables los medios de perfeccionar las técnicas docentes en el aula con el intuito de alcanzar el interés de los alumnos. Además, emprendemos una reflexión acerca de los aspectos generacionales que fomentan el éxito en la enseñanza de la lengua inglesa. La metodología utilizada es la de una revisión bibliográfica que entre los principales autores podemos destacar: Veiga (2007), Almeida Filho (2005), Rosa (2007) y Witter (2004) y Gardner (2001).

Palabras clave: Aprendizaje. Lengua Inglesa. Motivación

\section{Introdução}

O desinteresse de muitos alunos em meio às aulas de língua estrangeira tem levado a maioria dos educadores a repensarem o antigo 
e tradicional método de ensino, um comportamento que pode gerar notas baixas, pouco rendimento da aprendizagem e até evasão escolar. A maneira com que a Língua Inglesa é trabalhada em diversas escolas pode desmotivar alguns alunos.

Nesta análise, procuramos identificar fatores que poderiam motivar ou desmotivar os alunos no que tange ao processo ensino/aprendizagem em Língua Inglesa, observamos que alguns fatores internos como: o medo de errar, vergonha e timidez sobressaem entre os alunos, influenciando negativamente no aprendizado. Dentre os fatores externos, o método tradicionalista adotado pelo professor é o que mais desagrada e desmotiva os aprendizes. Isto posto, buscamos investigar as atividades que estimulam e as que desestimulam os alunos em sua trajetória escolar.

A pesquisa tem o objetivo de desvelar os fatores que promovem a disposição do aluno em aprender novas línguas; observar quais atividades são realizadas em sala de aula de língua inglesa; verificar quais atividades motivam os alunos nas aulas de inglês e, principalmente, averiguar quais atividades desmotivam os alunos. Essas ferramentas metodológicas partem no sentido de se buscar uma possível solução destes problemas por intermédio do ato de ensinar.

No decorrer do trabalho realizaremos uma revisão teórica sobre a motivação e seus reflexos sobre o indivíduo. Trata-se de uma pesquisa de cunho bibliográfico, a qual busca refletir acerca das análises de estudiosos da área, como Veiga (2007), Almeida Filho (2005), Rosa (2007) e Witter (2004). Observaremos o que os autores afirmam sobre a relevância que os fatores motivacionais intrínsecos e extrínsecos geram no comportamento do indivíduo e a responsabilidade em aprender.

No desafio de motivar o aluno é fundamental que o professor produza aulas mais dinâmicas, fazendo o aluno interagir e participar mais das aulas, integrando-se ao que está sendo ensinado.

O professor criativo, de espírito transformador, está sempre buscando inovar sua prática e um dos caminhos como tal fim seria dinamizar as atividades desenvolvidas em sala de aula. Uma alternativa para dinamização seria a variação das técnicas de ensino utilizadas; outra seria a introdução de inovação nas técnicas já amplamente conhecidas e empregadas (VEIGA, 2007, p.35). 
A Língua Inglesa está inserida no universo dos estudantes e já se tornou parte do nosso cotidiano, portanto é mister que o professor incuta no aluno que aprender o idioma lhe trará novas perspectivas intelectuais e, até mesmo, sociais. Buscaremos mostrar que o comportamento do professor, bem como seu relacionamento com os alunos precisa ser repensado.

O método tradicional de avaliação também pode desmotivar o aluno, provocando no uma grande angústia e sofrimento e fazendo com que este se preocupe demasiadamente com notas e menos com o aprendizado. $\mathrm{O}$ modo como o professor corrige os erros de seu aluno pode ser frustrante e/ou desestimulante para o indivíduo. Nesse caso, a discrição é fundamental, a correção também não pode ser constante e de forma veemente, isso poderia retardar o processo de ensino/aprendizagem, provocando descrédito por parte do aluno e, consequentemente, a não participação nas aulas.

\section{A motivação}

A motivação é de natureza sutil e complexa, trata-se de um fenômeno psicológico interior no qual as diferenças e aspirações individuais de cada aluno desempenham papel fundamental. Não existe uma regra ou técnica definida. Em sentido geral, a motivação pode e deve variar de acordo com o grupo a que se refere. A motivação se desvela como um fenômeno capaz de explicar o sucesso ou o fracasso de algumas atividades humanas.

As aprendizagens vão acontecer em função das necessidades do indivíduo; estas tendem a gerar um desequilíbrio, fazendo com que imediatamente sujam motivos; [...] assim podemos dizer que, para que ocorram as aprendizagens é necessário um estado de alerta (moderado), impulso, vontade e desejo de aprender, ou seja motivação (ROSA, 2007, p. 28).

A motivação apontada por Rosa (2007) se desvela como uma atividade emocional que produz atos conscientes e promove um período de esforço intelectual e/ou físico para atingir um objetivo preestabelecido. A motivação dos alunos sofre grandes influências de fatores internos e externos. Fatores internos são o interesse, a vontade e a confiança que tem em si mesmo. Já entre os fatores externos, podemos apontar a inte- 
ração, as experiências e as condições sociais entre as pessoas envolvidas no processo.

A relação professor-aluno se revela como um fator decisivo no sucesso dos aprendizes em relação ao aprendizado. Por intermédio do incentivo, o professor mexe com o interesse e a emoção do aprendiz, utilizando isso em motivação para obter conhecimento. $O$ professor precisa promover situações que despertem no aluno o desejo de aprender. É de suma importância que haja uma significativa interação em sala de aula, de maneira que o aluno também seja integrado no processo de aprendizagem.

Outra característica da aprendizagem é que ela acontece somente se houver da parte do educando, uma atividade autônoma no sentido de que ele se mobilize para o aprendizado. Significa dizer que a transmissão dos conteúdos, os conhecimentos científicos, as habilidades, atitudes etc., não é feita de maneira mecânica do professor para o aluno, sem que este queira (MELO; URBANETZ, 2008, p. 117).

O organismo age e reage em função de estímulos internos (fatores emocionais), dinâmicos (atitudes) e persistentes, os quais resultam nos motivos do comportamento. Para que o professor alcance essas duas áreas do comportamento do aluno, é fundamental que este seja despertado para o desejo de aprender a Língua Inglesa. Isso significa dizer que atrair a atenção e interesse do aluno para os valores contidos na matéria vai resgatá-lo de um estágio de letargia cognitiva, direcionando sua energia.

Importantes estudiosos do processo ensino/aprendizagem reconhecem a motivação com fator fundamental para que a aprendizagem ocorra. Os enfoques variam dependendo da linha psicológica adotada, mas é reconhecido que a pessoa interessada a aprender, o faz com muito maior facilidade e eficácia. A motivação para aprender ocorre internamente, entretanto, é importante uma atuação externa para que tal fenômeno ocorra. Alguém que, ao utilizar recursos e procedimentos adequados, proporcione ao aluno o interesse pelo conhecimento.

Observa-se um profundo distanciamento entre constatação teórica e experimental da prática escolar dos nossos dias. Tal fato se apresenta como uma barreira que se levanta, impossibilitando a solução de grandes entraves na aprendizagem, como a problemática da repetência, 
da evasão, da falta de adaptação da disciplina e tantos outros problemas clássicos da escolarização brasileira. Por que então as escolas ignoram a sua função motivadora? Por que se pressupõe, ingenuamente, que o aluno é obrigado a já vir motivado para a escola?

O diálogo é um dos fatores mais importantes na relação professor-aluno. A atitude dialógica no processo ensino-aprendizagem parte de uma questão problematizadora para desencadear o diálogo em que o professor transmite o que sabe, aproveitando os conhecimentos prévios e as experiências anteriores do aprendiz. Assim, ambos chegam a uma síntese que esclarece, explica ou resolve a situação-problema que desencadeou a discussão.

Convém lembrar que os elogios funcionam como reforço positivo, estimulando o aluno e ajudando-o a desenvolver um autoconceito positivo. Todavia, vale ressaltar que o elogio deve ocorrer em situações adequadas, ou seja, quando o professor perceber, realmente, que o aluno está se esforçando e fazendo o melhor que pode. Em meio a esse esforço, Witter (2004) enfatiza que promover a autoestima é fundamental,

um dos mais importantes componentes da autoestima positiva na criança é a aceitação de que ela seja como é, respeitando suabindividualidade. Outro passo é nunca perder o papel significativo que os professores representam na vida das crianças e como a concepção desses professores, de si e de cada criança, influem na forma de ensinar (WITTER, 2004, p. 59).

O domínio de uma segunda língua resulta de um investimento pessoal do indivíduo. Partindo desse pressuposto, o professor não consegue criar no aluno a atração por um idioma estrangeiro, porém o professor pode incentivar esse aluno, isto é, estimulá-lo externamente, captando e polarizando sua atenção e despertando o seu interesse. Para isso, é importante utilizar recursos e procedimentos incentivadores, aproveitando os fatores ambientais, não apenas no início da aula, mas durante todo o seu decorrer.

\section{Aprendizagem e motivação}

Conforme afirmação de Gardner e Lambert (1972, apud GÓMEZ, 1999), para que alguém aprenda é necessário que ele queira aprender. 
Ninguém consegue ensinar nada a uma pessoa que não quer aprender. Por isso, é muito importante que o professor consiga motivar os seus alunos. Por meio de uma variedade de recursos, métodos e procedimentos, o professor pode criar uma situação favorável à aprendizagem.

Para criar essa situação o professor deve:

- Conhecer os interesses atuais dos alunos para mantê-los ou orientá-los;

- Buscar uma motivação suficientemente eficiente, forte e duradoura, para conseguir do aluno uma atividade interessante e alcançar o objetivo da aprendizagem.

Entre motivação e aprendizagem existe uma mútua relação e ambas se reforçam.

A motivação da aprendizagem se traduz nos seguintes itens:

a) Sem motivação não há aprendizagem;

b) Os motivos geram novos motivos;

c) êxito na aprendizagem reforça a motivação;

d) A motivação é condição necessária, porém, não suficiente.

Desta forma, os alunos são envolvidos na experiência do conhecimento, interagindo e se tornando parte do processo. De acordo com Leffa $(2007$, p. 103) "o grau de atratividade e de eficiência dependerão da criatividade do professor".

O antigo método em que o professor se utiliza da fala expositiva durante horas, que na verdade cansa e irrita, não prende a atenção nem desperta a curiosidade e o interesse do aluno. Tal estratégia de ensino não contribui para um eficiente aprendizado, apenas massacra e o desgasta.

A consciência do indivíduo de suas necessidades desvela-se como uma espécie de motivação inicial. As metas, os valores e os propósitos ou objetivos do aluno influenciam para um determinado esforço do mesmo. Tudo que um aluno acredita que é importante para ele em algum aspecto, certamente, vai corroborar para que este se empenhe em alcançar, esforçando-se mais neste intuito.

De acordo com o pensamento construtivista, o indivíduo carrega consigo suas experiências, sejam elas boas ou ruins. Destarte, inúmeros fatores podem afetar o processo de aprendizagem de um aluno. Suas crenças, sentimentos, derrotas e/ou vitórias são elementos que constituem este aluno e influenciam no mecanismo da motivação. 
Nessa esteira, ressaltamos que motivação não ocorre isoladamente, mas pelo conjunto composto pelo aprendiz e professor no contexto, assim como pelas atividades. Este processo pode vir a sofrer alterações de acordo com as diferenças particulares de cada indivíduo.

\title{
Motivação relacionada à Língua Inglesa
}

As primeiras experiências do indivíduo com uma segunda língua são de suma importância na formação de uma personalidade integrada em seus aspectos emocionais e intelectuais.

\begin{abstract}
Vivemos uma época na qual o contato entre línguas e culturas nunca foi tão intenso e generalizado. O valor de transitarmos por outro idioma não precisa de muita defesa e já não se discute mais a ampliação de espaço de cultura em nós quando outra(s) língua(s) também nos constroem (ALMEIDA FILHO, 2005, p. 9).
\end{abstract}

Inicialmente o professor deve conhecer as características, interesses e necessidades do indivíduo para que possa adotar procedimentos que o conduzam à criação de um ambiente acolhedor e produtivo em sala de aula. Ademais, os aprendizes de uma língua estrangeira precisam de um sistema de educação que seja flexível no tempo e de material apropriado para o domínio de um conceito dado.

Para elevar a personalidade dos nossos alunos em relação ao ensino da língua inglesa é fundamental, antes de tudo, conhecê-los bem. Conhecer os alunos significa identificar seus traços, características, suas diferenças individuais, suas qualidades, defeitos e carências, e será de grande utilidade inventariar suas limitações e possibilidades reais.

Podemos afirmar que é em um ambiente de compreensão e afeto que o aprendiz se desenvolve de maneira segura. Sendo cada personalidade única por natureza, deve ser dirigida pelo professor. A este cabe selecionar instrumentos de aprendizagem adequados para que se alcance os objetivos propostos. Segundo Gardner e Lambert (1972, apud GÓMEZ, 1999), a aprendizagem, sendo uma atividade pessoal, reflexiva e sistemática, parte em busca de domínio sobre a cultura, os problemas da realidade e da vida exigindo dos alunos:

a) Atenção e esforço sobre novos campos de observação, estudo de atividade reflexiva; 
b) Autodisciplina, para realizar os estudos e cumprir as tarefas exigidas;

c) Perseverança nos estudos e nos trabalhos realizados, até adquirir o domínio da matéria de estudo em termos de utilidade real e da vida.

Para que o aluno aprenda o inglês, não basta explicar e exigir que entenda a língua alvo. Para aprender, é necessário despertar sua atenção, criar nele o legítimo interesse pela segunda língua, estimulando seu desejo de conseguir os resultados visando média, tarefas progressivas, cultivo do gosto pelos trabalhos relacionados ao inglês (GÓMEZ, 1999). Esse desejo, esforço e interesse de aprender são fatores internos.

O interesse evita a coação e o enfado, por conseguinte, despertar o interesse no aluno pela língua estrangeira promove uma aprendizagem mais eficaz. Afinal, o indivíduo só aprende bem aquilo em que estão realmente interessados.

Motivar é predispor o aluno ao que se quer ensinar; é leva-lo a participar ativamente na interação do grupo. Assim, motivar é levar o aprendiz a querer aprender uma segunda língua, ter gosto de estudar a língua inglesa e satisfação em aprender uma segunda língua. Um aluno está motivado quando sente necessidade de aprender o que está sendo tratado. Essa necessidade leva-o a aplicar-se, esforçar-se e perseverar no trabalho até sentir-se satisfeito.

Deve ser preocupação constante do professor motivar suas aulas. É a motivação que dá vida, espontaneidade e razão de ser à aula. A grande fonte de indisciplina em classe é a falha de motivação dos estudantes. De acordo com Ellis (1997), a motivação para aprender a língua inglesa se apresenta na forma de motivação instrumental, motivação integrada, motivação resultativa e motivação intrínseca.

Motivação instrumental é uma razão que impulsiona o indivíduo para obter sucesso (passar em exames, conseguir um bom emprego, garantir uma vaga na universidade), enfim, buscar a ascensão educacional e melhores oportunidades econômicas.

Motivação integrada busca domínio sobre a cultura, e problemas da realidade e da vida dos falantes da língua alvo.

Motivação resultativa é aquela em que o bom resultado do trabalho do aluno o impulsiona a querer ainda mais. A motivação nasce do sucesso de sua experiência anterior. 
Motivação intrínseca é o interesse positivo pela matéria em si como campo de estudo e de trabalho.

O dicionário HOUAISS (2001) define o termo 'motivo' como uma condição interna relativamente duradoura, que leva o aprendiz ou que o predispõe a persistir num comportamento dirigido para um objetivo, possibilitando a permanência ou a transformação da situação. O mesmo dicionário aponta que'motivação' é o processo que produz tais condições. Desta maneira, um comportamento motivado é a atividade assim produzida.

Embora motivação e incentivo sejam frequentemente usados como se fossem a mesma coisa, não são sinônimos. Incentivo refere-se ao objeto ao qual a atividade se dirige, à condição ou mudança de comportamento, de condição que desperta ou satisfaz o motivo de interesse de aprender uma segunda língua. São exemplos de incentivo: o alimento, o sexo, o dinheiro, as notas escolares, os prêmios e os diplomas. Os incentivos são objetos, condições ou significações externas para as quais os motivos se dirigem. A motivação refere-se a uma condição persistente, usualmente uma condição interna do indivíduo, tal como a fome crônica ou o desejo insatisfeito de obter prestígio.

O papel do professor em meio ao ensino de uma segunda língua não é criar novos motivos, os quais são consequências de muitos fatores culturais, mas sim, manipular e possibilitar a incorporação de novos significados, objetos e ideias ao universo interior do aluno em relação à aprendizagem da nova língua.

De acordo com Gardner (2001, p. 129), "the motivationis a central element [...] in determining success in learninga notherlanguage in theclassroom setting", ou seja, a motivação é um elemento central para determinar o sucesso na aprendizagem de línguas em ambientes de sala de aula. Depreende-se da fala de Gardner que alguns fatores, como por exemplo: material didático diferenciado, ambiente adequado, entre outros, corroboram bastante para o aprendizado de uma língua estrangeira, todavia, se o aluno não estiver interessado em aprender não se obterá o sucesso desejado, pois motivos, incentivos e significados relacionam-se dinamicamente. $O$ professor de uma língua estrangeira pode auxiliar o aluno a passar de uma dependência de incentivos externos, específicos e imediatos (motivação extrínseca) para incentivos mais remotos e generalizados (motivação intrínseca).

Dada a natureza complexa da motivação da língua inglesa como fenômeno psicológico interior, o qual as diferenças individuais e a expe- 
riência prévia de cada aluno desempenham um papel importante, não é possível traçar uma técnica padronizada, segura e infalível para provocar a desejada motivação interior para aprendizagem do inglês. Contudo, deve-se procurar estabelecer procedimentos que estimulem o interesse do aluno.

O estímulo da aprendizagem da Língua Inglesa é a atuação externa, intencional e bem calculada do professor para - mediante meios auxiliares, recursos e procedimentos adequados - intensificar em seus alunos a motivação interior necessária para uma autêntica e eficaz aprendizagem.

Os fatores internos estão relacionados ao interesse pela aula, à atitude positiva com relação à Língua Inglesa e à noção de autoconceito. Os fatores afetivos e os fatores externos relacionados à interação com os outros e o método estão diretamente ligados à motivação dos aprendizes da língua inglesa para a participação e interação em sala de aula. “O filtro afetivo é uma barreira que impede os aprendizes de uma língua estrangeira de adquirir uma linguagem de forma apropriada" (VIVIAN, 2005, p. 5).

O método de ensinar pode facilitar ou dificultar o processo de aprendizagem e estímulo dos alunos. O que o professor faz ou deixa de fazer influencia neste processo. Prova disso são as inovadoras dinâmicas de ensino adotadas nas escolas, que buscam uma maior interação com os alunos, facilitando e promovendo a motivação no aluno. Os fatores afetivos se enquadram na interação e no interesse dos alunos de uma segunda língua, nesse caso a língua inglesa, motivando e os impulsionando no desejo de aprender. Devemos levar em conta que a interação pode variar de acordo com características de personalidade e também de ambiente.

\begin{abstract}
Outra característica da aprendizagem é que ela acontece somente se houver da parte do educando, uma atividade autônoma no sentido de que ele se mobilize para o aprendizado. Significa dizer que a transmissão dos conteúdos, os conhecimentos científicos, as habilidades, atitudes etc., não é feita de maneira mecânica do professor para o aluno, sem que este queira. (MELO; URBANETZ, 2008, p. 117)
\end{abstract}

Seja qual for o fator determinante, o que não pode deixar de haver é a interação dentro de uma sala de aula, visto que, ao contrário do que se acreditava, não é apenas o professor que determina os procedimentos e os rumos do conteúdo, mas também as atitudes dos alunos. 


\section{Motivação intrínseca}

A vontade de aprender é um elemento determinante para a obtenção de resultados positivos no ensino de uma segunda língua. A motivação atua exatamente no ponto determinante da aprendizagem, que é elevar primeiramente a autoestima do aluno sem propósito e que se julga incapaz de assimilar uma segunda língua pelos mais variados motivos, suscitando nele a disposição para aprender.

A falta de motivação é causada por características pessoais do aluno e contexto da escola. Alguns alunos não se envolvem em uma ou outra atividade, outros se fecham completamente ao saber - não querem participar e nada fazem para aprender.

O medo do fracasso e a forma de encará-lo, a falta de clareza sobre os objetivos da aprendizagem e a não satisfação das expectativas são alguns dos motivos de ordem pessoal. Além deles, existem as influências de pais, colegas e grupos sociais, mais as experiências anteriores de cada um. Junta-se a isso o ambiente da escola e da sala de aula para o desenvolvimento das atividades, como a organização, a interação com o professor e a avaliação.

Conforme Dalacorte (2000, p. 47), a decisão de participar é dos aprendizes, as estratégias que utilizam para interagir refletem seus motivos para agir em sala de aula. Os fatores internos estão relacionados ao interesse pela aula, à atitude positiva com relação à Língua Inglesa, à noção de autoconceito; enquanto os fatores externos referem-se à interação com os outros e ao método utilizado pelo professor. Portanto, observamos que os fatores afetivos e os fatores externos estão diretamente ligados à motivação dos aprendizes, ambos atuam como agentes determinantes de uma interação positiva do aluno em sala de aula.

Existem alunos que buscam aprender uma segunda língua pelo prazer de aprender, pela satisfação interior que apreendem desta atividade. Podemos afirmar, então, que existe um certo número de pessoas que sentem uma satisfação real no estudo em geral e, por conseguinte, no estudo de línguas.

O meio em que o aluno vive pode favorecer indiretamente, se não provocar e suscitar esta motivação interna. Como exemplo, tomemos uma família em que os pais consideram o estudo de línguas importante, os filhos serão mais motivados e vão prosperar mais 
no aprendizado do que numa família com pouco interesse em aprender (SANTANA; BARROS, 2002).

Depreende-se da constatação dos autores que o meio social do indivíduo reflete no interesse dele pela aprendizagem de uma língua estrangeira. Os valores vivenciados pelo indivíduo no meio familiar influenciam de forma determinante seus anseios intelectuais. Destarte, a motivação neste ponto inclina-se para um processo psicológico e social, o que já não é mais da responsabilidade apenas do professor.

\title{
Motivação extrínseca
}

A motivação extrínseca vem de fora, como por exemplo, as necessidades e os anseios do aluno em conseguir algo, assim como as influências do grupo e família, cobranças sociais, entre outros. São fatores que acabam por influenciar de modo positivo ou negativo no comportamento do aluno, promovendo ou não a motivação intrínseca.

Motivos como notas, aprovação no final do ano e estímulo familiar por médias mais elevadas são fatores externos que levam o aluno a estudar. A psicóloga Evely Boruchovitch, doutora pela University of Southern California e responsável pelo Departamento de Psicologia Educacional da Faculdade de Educação da Universidade Estadual de Campinas (UNICAMP), afirma que se pode efetivamente suscitar ou desenvolver a motivação:

\begin{abstract}
A motivação intrínseca do aluno não resulta de treino ou de instrução, mas pode ser influenciada principalmente pelas ações do professor. Embora não se desconsiderem as crenças, conhecimentos, expectativas e hábitos que os estudantes trazem para a escola, a respeito da aprendizagem e da motivação, o contexto instrucional imediato, ou seja, a sala de aula torna-se fonte de influência para o seu nível de desenvolvimento (BORUCHOVITCH; GUIMARÃES, 2004, p. 147)
\end{abstract}

Cabe ao professor despertar no aluno o interesse pela Língua Inglesa, mostrando a importância e necessidade desse idioma para a vida intelectual e profissional do aluno. É crucial planejar aulas mais atrativas, atividades dinâmicas, transportar a matéria para o meio em que o aluno convive, permitindo que o aluno se expresse e experimente o prazer de se comunicar por meio da língua inglesa. 
A função do professor é, também, despertar no aluno a curiosidade e a vontade de conhecer uma segunda língua, mostrando a ele que pode ser divertido e interessante adquirir um novo aprendizado, e lembrá-lo sempre da importância e a utilidade de aprender inglês. Segundo o psicólogo Bzuneck (2003) da Universidade de Londrina, independente da série, é possível ao professor manter alto o nível de motivação nas aulas de Língua Inglesa utilizando as seguintes estratégias:

- Mostrar-se entusiasmado com os conteúdos que está ensinando;

- Despertar a curiosidade destacando a relação do conteúdo com fatos cotidianos;

- Orientar a aprendizagem para compreensão e não para a memorização;

- Elaborar atividades que mostrem como o aluno evolui;

- Usar um ritmo que permita que todos acompanhem o encadeamento de ideias;

- Mudar a estratégia ao perceber que os alunos não aprenderam;

- Estabelecer metas realistas e explique detalhadamente os objetivos, combinando regras;

- Dar pistas de como superar as dificuldades sem revelar, de imediato, a solução;

- Evitar avaliações negativas, comparativas e ameaçadoras da autoestima dos alunos.

Dentre algumas estratégias interessantes para despertar a curiosidade e atrair os alunos desmotivados pelas aulas de Língua Inglesa, podemos destacar as músicas e filmes produzidos fora do Brasil, jogos educativos e sites em inglês presentes da rede internacional de computadores - internet e produtos com nomes em inglês utilizados por eles no dia a dia. Tudo isso faz parte do universo pessoal dos jovens aprendizes e, certamente, é uma forma de o professor destacar o grau de importância de se aprender inglês e conquistar o interesse desse aluno. "A ênfase está na diversão, uma vez que os aprendizes veem um filme com o propósito de imergir na língua." (LEFFA, 2007, p. 53). 


\section{Considerações finais}

Nesta análise buscamos mostrar a importância da motivação no aprendizado de uma segunda língua. Entendemos que o incentivo é o principal fator que desperta no aluno o interesse do saber. Buscar o conhecimento de uma língua estrangeira é algo que requer disposição e vontade do aluno, do professor e até mesmo da família, a qual vem atuar diretamente e indiretamente no processo da motivação. Quando os pais motivam e auxiliam no processo da aprendizagem dos filhos em meio ao ambiente familiar, a tendência é alavancar o desejo e interesse desses alunos pelos estudos, visto que o aspecto afetivo é de suma importância na busca pelo conhecimento.

O papel do professor é buscar o aluno para se envolver no aprendizado da Língua Inglesa, adaptando meios mais atrativos para tornar as aulas mais agradáveis, despertando o interesse do aluno. Uma das maneiras do docente conseguir atrai-lo é fazer com que este participe das aulas, seja ativo, evitando ao máximo a passividade dos aprendizes e o tédio em sala de aula, distanciando-se do método tradicional de transmitir um conteúdo enquanto os alunos apenas o recebem. $O$ professor de língua estrangeira deve estar sempre buscando novas maneiras de motivar o interesse do aluno e se atualizar constantemente a despeito de metodologias diversificadas de ensinar.

Uma das formas do professor despertar no aluno o interesse de aprender a Língua Inglesa é provocar neles a curiosidade e a vontade de dominar um idioma tão importante em meio ao mundo globalizado em que vivemos. Atualmente, os alunos se preocupam muito com notas e médias semestrais, isto se dá porquanto não se sentem motivados a aprender realmente. Todavia, estudar não pode ser visto como algo maçante e cansativo.

Para o professor de Língua Inglesa, a satisfação de dar aulas para alunos interessados é muito maior e isso será possível mediante um bom planejamento. Outrossim, criar um ambiente motivador e gerar no aprendiz o interesse pelo saber é fundamental. Será gratificante verificar que as médias ao fim de cada semestre serão apenas consequência de aulas bem trabalhadas e produtivas.

Concluímos que a Língua Inglesa não pode e nem deve ser tratada como mais uma das disciplinas que integram a matriz curricular das escolas, mas que seja apresentada ao estudante como uma oportunida- 
de de aprender o idioma mais utilizado nos dias de hoje em todo o mundo. Desse modo, o professor não deve se pautar apenas em regras gramaticais ou na pronúncia de algumas palavras, é imprescindível ensinar o aluno a ouvir, ler, escrever e, principalmente, falar inglês. De maneira a capacitar o aprendiz a utilizar a língua inglesa em variados contextos.

Os alunos se interessariam mais em aprender inglês e participar das aulas se lhes fossem propostas atividades mais dinâmicas e atraentes, em que o professor dotasse recursos que fazem parte do dia a dia desses estudantes, como: músicas, vídeos, filmes, jogos, etc. Estas e outras metodologias têm o poder de amalgamar aprendizagem e prazer.

A motivação do aluno ainda não é totalmente empreendida em meio às aulas de Língua Inglesa, ainda há muito o que se pensar sobre isso e também muito a ser feito, visando ampliar o interesse dos discentes pela língua estrangeira. Depreende-se que os professores sejam orientados e capacitados a explorar o estilo motivacional no processo ensino/aprendizagem, principalmente no que tange à motivação intrínseca, planejando estratégias que corroborem para elevar o nível de interesse pelas aulas e, consequentemente, alavancar o bom desempenho dos aprendizes de Língua Inglesa.

\section{Referências}

ALMEIDA FILHO, J. C. P. Linguística Aplicada: ensino de línguas e comunicação. São Paulo: Pontes, 2005.

BORUCHOVITCH, E.; GUIMARÃES, S. E. R. O Estilo Motivacional do Professor e a Motivação Intrínseca dos Estudantes: Uma Perspectiva da Teoria da Autodeterminação. Psicologia: Reflexão e Crítica, v.17, n. 2, p. 143-150, 2004.

BZUNECK, J. A. Como lidar com alunos desmotivados. Nova Escola, Editora Abril, no. 159, p. 14, jan./fev. 2003.

DALACORTE, M. C. F. A participação dos aprendizes na interação em sala de aula. In: MELLO, H. A. B. de; DALACORTE, M C. F. (Org.). A sala de aula de língua estrangeira. Goiânia, Editora UFG, 2000. P. 39-62.

ELLIS, R. Second Language Acquisition. Oxford: Oxford University Press, 1997.

GARDNER, R. C. Estruturas da mente: a teoria das inteligências múltiplas. 
Porto Alegre: Artes Médicas, 2001.

GÓMEZ, P.C. A Motivação no Processo Ensino/Aprendizagem de ldiomas: um Enfoque Desvinculado dos Postulados de Gardner e Lambert. Trabalhos de Linguística Aplicada, v. 34, p.53-78, jul/dez 1999.

HOUAISS, A.; VILLAR, M.; FRANCO, F. M. M., Instituto Antônio Houaiss. Dicionário Houaiss da língua portuguesa. Rio de Janeiro: Objetiva, 2001.

LEFFA, Vilson J. (Org.) Produção de matérias de ensino: teoria e prática. Pelotas: EDUCAT, 2007.

MELO, A.; URBANETZ, S. T. Fundamentos de Didática. Curitiba: Editora IBPEX, 2008.

ROSA, J. L. (Org.). Psicologia e Educação: o significado do aprender. Porto Alegre: EDIPUCRS, 2007.

SANTANA, L. S. A.; BARROS, M. da S. A Importância do Ensino de Inglês para Crianças. 2002. Monografia (Graduação em Letras: Português/ Inglês) - Universidade Estadual de Goiás, Unidade Universitária de Itapuranga.

WITTER, G. P (Org.). Psicologia e Educação: professor ensino e aprendizagem.Campinas: Alinea editora, 2004.

VEIGA, I. P. A. (Org.). Técnicas de ensino: por que não? Campinas-SP: Papirus Editora, 2007.

VIVIAN, M. A influência do aspecto afetivo na aprendizagem da Língua Inglesaem escolas públicas. Revista Voz das Letras. Concórdia/Santa Catarina: Universidade do Contestado, n. 3, 2005.

Recebido em: Julho/2019

Aceito em: Fevereiro/2020 